\title{
Is there any Association between Biofilms and COVID-19?
}

ISSN: 2637-7764

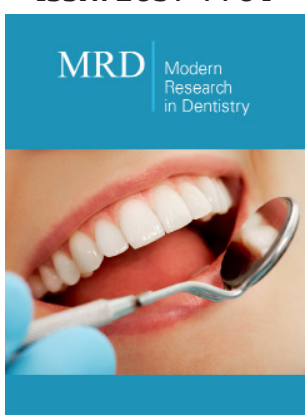

*Corresponding author: Rabia Sannam Khan, ICE Postgraduate Dental Institute and Hospital, 24 Furness Quay, Salford, UK

Submission: 眥 November 11, 2020

Published: 盟 November 20, 2020

Volume 5 - Issue 5

How to cite this article: Rabia Sannam Khan*, Yasser Ali H Almoshawah, Hafsah Akhtar, Fahad $\mathrm{H}$ Alhamoudi. Is there any Association between Biofilms and COVID-19?. Mod Res Dent. 5(5). MRD. 000621. 2020

DOI: 10.31031/MRD.2020.05.000621

Copyright@ Rabia Sannam Khan, This article is distributed under the terms of the Creative Commons Attribution 4.0 International License, which permits unrestricted use and redistribution provided that the original author and source are credited.

\section{Rabia Sannam Khan ${ }^{1 *}$, Yasser Ali H Almoshawah ${ }^{2}$, Hafsah Akhtar ${ }^{3}$ and Fahad H Alhamoudi ${ }^{4}$}

${ }^{1}$ Rabia Sannam Khan, PhD scholar, ICE Postgraduate Dental Institute and Hospital, 24 Furness Quay, Salford, UK

${ }^{2}$ Yasser Ali H Almoshawah, Lecturer, Department of Mechanical Engineering, Shaqra University, Saudi Arabia

${ }^{3}$ Hafsah Akhtar, PhD Scholar, Department of Material Science and Engineering, University of Sheffield, UK

${ }^{4}$ Fahad Hussain, Lecturer, Department of Dental Technology, King Khalid University, Saudi Arabia

\section{Opinion}

The global pandemic COVID-19 has brought devastating health, social and economic effects that drastically impacts the health services delivery. The route of entry of the SARSCOV-2 is respiratory system where it disturbs the equilibrium. The miscommunication between the adaptive and innate immunity is the indirect cause of death in patients suffering from COVID-19 severe symptoms. The failure in the production of effective antibodies against the virus causes the mortality. This shows that the adaptive immune response takes longer than the innate immune response. It is proposed that bacterial biofilms can be similar to viral biofilms representing the viral communities with augmented infectious capacity [1].

Biofilms occurs when the microorganisms accumulate and binds to a surface, and forms layers and hence stabilizes the bacterial infections and associated resistance. Biofilms causes not only bacterial infectious diseases but also viral diseases. Biofilms accumulate in viral infections and despite having the common features between bacterial and viral biofilms the major difference is being that the matrix of viral assembly is formed by the infected cell whereas the bacterial biofilm matrix is formed by the microbe itself. Biofilms can be found in different environments such as in teeth, stomach where the bacteria start to cause an infection [2].

SARS-COV-2 transmission is relying on the production of extracellular viral particles and the concentration, structure, function and composition of the viral particles are similar to those of the bacterial biofilms. SARS-COV-2 is an RNA virus which is encapsulated with proteins and lipid layer. The virus floats in air and attach to surfaces due to the lipid membranes that altogether makes very frail membranes, therefore, if the virus were single having no poli-viral support, it won't survive in the conditions. It is 50 to $200 \mathrm{~nm}$ in diameter and it contains the spike, envelope, membrane and nucleocapsid proteins. The spike protein attaches and fuses and triggers the viral host cell membranes. The S1 subunit of spike protein further engages the host cell receptor, the S1 receptor binding domain undergoes conformational motions. The host cell receptor is angiotensin converting enzyme 2, which has the higher affinity to SARS-COV-2 in comparison to SARS-COV. The protease domain of angiotensin converting enzyme engages the alpha 1 helix, in the recognition of receptor binding domain and engages with minor contribution from alpha2 helix and beta 3 and 4 sheets $[3,4]$. 
These undergoing processes allows to suspect the inter viral membrane activity that makes the viral biofilm possibility and hence, the membrane destruction might leads to shorter viral life span and viral isolation. This also allows virus to infect other tissues such as liver cells, erythrocytes, nephrons, neurons and many more [4]. The better understanding concentration of accumulated mutant viral particles beneath each layer of biofilm is important. Further investigation is required to identify the biofilm formation possibility for SARS-COV-2.

\section{References}

1. Thoulouze MI, Alcover A (2011) Can viruses form biofilms? Trends Microbiol 19(6): 257-262.
2. Penesyan A, Nagy SS, Kjelleberg S, Gillings MR, Paulsen IT (2019) Rapid microevolution of biofilm cells in response to antibiotics. NPJ Biofilms Microbiomes 5(1): 34 .

3. Saeid B, Parissa F, Poopak F, Jalaledin G, Akbar VA (2020) Investigation of the hypothesis of biofilm formation in coronavirus (COVID-19). Biomedical and biotechnology research journal 4(5): 99-100.

4. Duarte AT, Ramírez VG (2020) COVID-19, SARS-CoV-2 encapsulated RNA Virus is capable of forming a viral biofilm. 